\title{
Clinical Indicators for Long-Term Survival with Immune Checkpoint Therapy in Advanced Hepatocellular Carcinoma
}

\author{
Cecilia Monge (D) \\ Changqing Xie' \\ Seth M Steinberg ${ }^{2}$ \\ Tim F Greten ${ }^{1,3}$
}

'Gastrointestinal Malignancies Section, Thoracic and GI Malignancies Branch, Center for Cancer Research, National Cancer Institute, National Institutes of Health, Bethesda, MD, 20892, USA;

${ }^{2}$ Biostatistics and Data Management Section, Center for Cancer Research, National Cancer Institute, National Institutes of Health, Bethesda, MD, 20892, USA; ${ }^{3} \mathrm{NCl}$ CCR Liver Cancer Program, National Institutes of Health, Bethesda, MD, 20892, USA
Correspondence: Tim F Greten

Tel + 2 240-760-6II4

Email tim.greten@nih.gov
Introduction: Patients with advanced hepatocellular carcinoma have a dismal prognosis; only a subset of patients with advanced HCC will benefit from treatment with immunotherapy. We searched for clinical characteristics predicting exceptional long-term survival in HCC patients treated with immune checkpoint inhibitors.

Methods: We compared clinical characteristics of 59 patients with advanced hepatocellular carcinoma treated with immunotherapy with and without locoregional therapy between 2013-2019. We compared patients who lived less than 12 months with patients who lived more than 3 years. Traits of short-term (31 patients) and long-term (5 patients) survivors were compared. Patients who died between 12 months and 3 years of starting treatment on protocol were not included in the analysis.

Results: Two out of five patients (40\%) in the long-term survival group had a partial response (PR) or a complete response (CR) per the modified Response Evaluation Criteria in Solid Tumors (mRECIST), while, of the 31 patients in the short-term survival group, only $2(6.5 \%)$ had a CR or PR. Two of the 5 patients with a long-term survival had immunerelated adverse events grade 3 or 4 (IrAEs-3/4). None of the patients in the short-term survival group had IrAEs-3/4. The patients, who presented with IrAEs-3/4, which included colitis and adrenal insufficiency, continued to have a response off treatment. The median overall survival (OS) was 11.8 months (95\% CI: 7.8-15.4 months), with a 12-month OS of $46.6 \%$ (95\% CI: $33.4-58.8 \%$ ) and a 3 -year OS of $12.5 \%$ (95\% CI: $5.0-23.7 \%$ ).

Conclusion: We found a possible association between immune-related adverse events grade 3 and 4 and long-term survival in patients with advanced HCC. The cases in our analysis represent extraordinary defiance of the usual predicted dismal course of advanced HCC.

Keywords: hepatocellular carcinoma, immunotherapy, long-term overall survival, immunerelated adverse events, tremelimumab, durvalumab

\section{Introduction}

Patients with advanced hepatocellular carcinoma have a dismal prognosis. ${ }^{1}$ In the last three and a half years, four immune checkpoint inhibitors have received FDA approval for the treatment of advanced HCC in the first- or second-line setting, transforming current standards of care. ${ }^{2-4}$ Only a subset of patients with advanced HCC will benefit from treatment with immunotherapy, which highlights a pressing need to identify predictive characteristics of a good response to treatment. We searched for clinical characteristics predicting exceptional long-term survival in HCC patients treated with immune checkpoint inhibitors in clinical trials. 


\section{Materials and Methods}

From July 2013 to November 2019, we enrolled 59 patients with advanced $\mathrm{HCC}$ on two clinical trials testing the combination of tremelimumab ${ }^{5}$ or tremelimumab plus durvalumab and locoregional therapy (NCT01853618, NCT03937830). We compared patients who lived less than 12 months (31 patients) with patients who lived more than 3 years ( 5 patients). Patients who died between 12 months and 3 years of starting treatment on protocol were not included in the analysis. Traits of short- and longterm survivors were compared using Fisher's exact test for dichotomous traits. A Cochran-Armitage test was used to identify the alpha fetoprotein (AFP) trend and an exact Wilcoxon rank sum test was used to compare ages and prior duration of treatment with sorafenib.

\section{Results}

Comparison of the clinical characteristics of the two groups included age, sex, duration of sorafenib treatment prior to study, AFP value, response to treatment per RECIST criteria, tumor burden and immune-related adverse events grade 3 or 4 (IrAEs- 3/4) (Table 1). Alphafeto-protein values were allocated to three arbitrary categories: 1 to $20 \mathrm{ng} / \mathrm{mL}$ (1), 21 to $1000 \mathrm{ng} / \mathrm{mL}$ (2) and 1001 $\mathrm{ng} / \mathrm{mL}$ or higher (3). High tumor burden was arbitrarily defined as a tumor with a diameter of $>5 \mathrm{~cm}$ at start of treatment in the study. Five patients had impressive survivals, ranging from 40 to 74 months; 31 patients died in the first year. The median age was 64 years in the long-term survival patients and 61.8 years in the short-term survival group; most patients had an Eastern Cooperative Oncology Group (ECOG) of 1. As expected for HCC from an epidemiological perspective, most patients were male; all patients in the long-term survival group and approximately $65 \%$ of patients in the short-term survival group were male. Hepatitis C-related cirrhosis was the most common underlying liver disease in both groups, followed by hepatitis B. Most patients in both groups had a Child-Pugh score consistent with class A. Patients in the long-term survival group received a mean of 6.2 months of treatment with sorafenib prior to enrollment compared to 4.2 months of treatment in the short-term survival group. Approximately $40 \%$ of patients in both groups had AFP values in category 3 . A high tumor burden was present in 4 of 5 patients $(80 \%)$ with long-term survival and in 22 of 29 patients $(75.9 \%)$ with short-term survival. In the group of patients with long-term survival, 2 out of 5 (40\%) had a partial response $(\mathrm{PR})$ or a complete response $(\mathrm{CR})$ per the modified Response Evaluation Criteria in Solid Tumors (mRECIST), ${ }^{6}$ while within the 31 patients in the short-term survival group only $2(6.5 \%)$ of 31 patients had a CR or PR. Two of the 5 patients with a long-term survival had IrAEs- 3/4. None of the patients in the shortterm survival group had IrAEs-3/4. The 2 patients who presented with IrAEs-3/4, which included colitis and adrenal insufficiency, continued to have a response off treatment. The median overall survival (OS) was 11.8 months (95\% CI: 7.8-15.4 months), with a 12-month OS of $46.6 \%$ (95\% CI: $33.4-58.8 \%)$ and a 3 -year OS of $12.5 \%(95 \%$ CI: $5.0-23.7 \%$ ).

Two of the five patients with long-term survival died of non-HCC-related causes, including myocardial infarction and cerebrovascular accident, and two patients are still alive. The five long-term survival patients all received treatment with locoregional therapy prior to enrolling on the study, two underwent a partial hepatectomy and three were treated with sorafenib (treatment duration ranged from 2 to 6 months). Three patients were considered Barcelona Clinic Liver Cancer (BCLC) B with HCC limited to the liver, one patient had metastatic disease to soft tissue, and one had metastatic disease to both soft tissue and bone. Three patients had underlying hepatitis $\mathrm{C}$ as the cause of cirrhosis. One patient did not have any known underlying liver disease. The range of time from diagnosis to enrollment on study was between 3 and 58 months. The overall survival in the five long-term survival patients ranged from 40 to 74 months. Three patients received locoregional treatment in combination with immunotherapy while on study and two patients received combination immunotherapy with durvalumab and tremelimumab. As a group, they received between 6 and 40 cycles of treatment on study. Two patients in the long-term survival group came off study because of $\mathrm{PD}$, one patient came off because of colitis which was classified as an IrAE, one patient discontinued treatment after 38 cycles due to personal preference and one patient continues on study (Table 2).

\section{Discussion}

We provide a unique insight into long-term survival of patients with advanced HCC treated with immune checkpoint inhibition (ICI) by comprehensively analyzing clinical characteristics that may identify the subset in which treatment results in prolonged disease control. Although $20 \%$ of patients with advanced $\mathrm{HCC}$ are expected to have a response 
Table I Characteristics of Patients

\begin{tabular}{|c|c|c|c|c|}
\hline & Value & Long-Term Survival Patients & Short-Term Survival Patients & \\
\hline No. of patients & & 5 & 31 & \\
\hline Age at treatment, years & $\begin{array}{l}\text { Mean } \\
\text { Std error } \\
\text { Minimum } \\
\text { Median } \\
\text { Maximum } \\
\text { p-value }\end{array}$ & $\begin{array}{l}63 \\
2.2 \\
57 \\
64 \\
69\end{array}$ & $\begin{array}{l}61.8 \\
1.9 \\
35 \\
63 \\
81\end{array}$ & 更 \\
\hline Sex & $\begin{array}{l}\text { Female, n (\%) } \\
\text { Male, n (\%) } \\
\text { P-value }\end{array}$ & $\begin{array}{l}0 \\
5(100 \%)\end{array}$ & $\begin{array}{l}\text { II (35.5\%) } \\
20(64.5 \%)\end{array}$ & 0.29 \\
\hline Sorafenib duration of treatment in months & $\begin{array}{l}\text { Mean } \\
\text { Std error } \\
\text { Minimum } \\
\text { Median } \\
\text { Maximum } \\
\text { p-value }\end{array}$ & $\begin{array}{l}6.2 \\
2.4 \\
2 \\
6 \\
15\end{array}$ & $\begin{array}{l}4.2 \\
0.8 \\
0 \\
4 \\
18\end{array}$ & 0.41 \\
\hline AFP & $\begin{array}{l}\text { Category I, n (\%) } \\
\text { Category 2, n (\%) } \\
\text { Category 3, n (\%) } \\
\text { p-value }\end{array}$ & $\begin{array}{l}2(40 \%) \\
\text { I (20\%) } \\
2(40 \%)\end{array}$ & $\begin{array}{l}8(28.6 \%) \\
9(32.1 \%) \\
I I(39.3 \%)\end{array}$ & 1.00 \\
\hline Response to treatment & $\begin{array}{l}C R \text { or } P R \\
S D \text { or } P D \\
P \text {-value }\end{array}$ & $\begin{array}{l}2(40 \%) \\
3(60 \%)\end{array}$ & $\begin{array}{l}2(6.5 \%) \\
29(93.5 \%)\end{array}$ & 0.084 \\
\hline Tumor burden & $\begin{array}{l}\text { High } \\
\text { Low } \\
\text { p-value }\end{array}$ & $\begin{array}{l}4(80 \%) \\
\text { I (20\%) }\end{array}$ & $\begin{array}{l}22(75.9 \%) \\
7(24.1 \%)\end{array}$ & 1.00 \\
\hline IrAE grade $3-4$ & $\begin{array}{l}\text { Yes } \\
\text { No } \\
\text { p-value }\end{array}$ & $\begin{array}{l}2(40 \%) \\
3(60 \%)\end{array}$ & $\begin{array}{l}0(0 \%) \\
31(100 \%)\end{array}$ & 0.016 \\
\hline ECOG & $\begin{array}{l}0 \\
1\end{array}$ & $\begin{array}{l}2 \\
3\end{array}$ & $\begin{array}{l}10 \\
21\end{array}$ & \\
\hline Liver cirrhosis & $\begin{array}{l}\text { Yes } \\
\text { No }\end{array}$ & $\begin{array}{l}4 \\
1\end{array}$ & $\begin{array}{l}24 \\
7\end{array}$ & \\
\hline Cause of liver disease & $\begin{array}{l}\text { Hepatitis B } \\
\text { Hepatitis C } \\
\text { Other }\end{array}$ & $\begin{array}{l}1 \\
3 \\
1\end{array}$ & $\begin{array}{l}9 \\
22\end{array}$ & \\
\hline Child-Pugh score & $\begin{array}{l}5 \\
6 \\
7 \\
\text { NA }\end{array}$ & $\begin{array}{l}2 \\
2 \\
1\end{array}$ & $\begin{array}{l}17 \\
10 \\
4\end{array}$ & \\
\hline $\mathrm{BCLC}$ & $\begin{array}{l}\text { B } \\
C\end{array}$ & $\begin{array}{l}3 \\
2\end{array}$ & $\begin{array}{l}13 \\
18\end{array}$ & \\
\hline
\end{tabular}

Abbreviations: No., number; Std error, standard error; AFP, alpha fetoprotein; IrAE, immune-related adverse event; ECOG, Eastern Cooperative Oncology Group; BCLC, Barcelona Clinic Liver Cancer. 
Table 2 Characteristics of Patients with Long Survival

\begin{tabular}{|c|c|c|c|c|c|}
\hline Case & I & 2 & 3 & 4 & 5 \\
\hline Age* (years) & 57 & 59 & 69 & 64 & 66 \\
\hline Overall survival (months) & 74 & 68 & 60 & 44 & 40 \\
\hline Months on study & 6 & 8 & 17 & 38.8 & 40 \\
\hline Treatment & T, TACE & $\mathrm{T}+\mathrm{D}, \mathrm{TACE}$ & $\mathrm{T}+\mathrm{D}, \mathrm{TACE}$ & $T+D$ & $T+D$ \\
\hline Reason off study & irAE (colitis) & PD & PD & Patient preference & On study \\
\hline Treatment before & RFA & $\begin{array}{c}\text { RFA } \\
\text { TRCI05 } \\
\text { Sorafenib }\end{array}$ & $\begin{array}{c}\text { Partial } \\
\text { Hepatectomy } \\
\text { TACE }\end{array}$ & $\begin{array}{c}\text { Partial } \\
\text { Hepatectomy } \\
\text { RFA } \\
\text { HIGRT } \\
\text { Sorafenib }\end{array}$ & $\begin{array}{c}\text { TACE x } 4 \\
\text { RFA } \\
\text { SBRT } \\
\text { TRCI05 } \\
\text { Sorafenib }\end{array}$ \\
\hline $\begin{array}{l}\text { Duration of sorafenib } \\
\text { treatment (months) }\end{array}$ & 0 & 5 & 0 & 2 & 6 \\
\hline $\begin{array}{l}\text { Disease site upon } \\
\text { enrollment }\end{array}$ & Liver & Liver & Liver & Liver soft tissue & $\begin{array}{l}\text { Liver soft } \\
\text { tissue, } \\
\text { bone }\end{array}$ \\
\hline $\begin{array}{l}\text { Time between diagnosis } \\
\text { and start of } \mathrm{ICl} \text { treatment } \\
\text { (months) }\end{array}$ & 8 & 14 & 3 & 25 & 58 \\
\hline Treatment after & $\begin{array}{l}\text { TACE } \\
\text { EBRT }\end{array}$ & Lenvatinib & TACE & None & On study \\
\hline Risk factor & HBV & - & $\mathrm{HCV}$ & $\mathrm{HCV}$ & $\mathrm{HCV}$ \\
\hline CP score** & 5 & - & 5 & 5 & 5 \\
\hline BCLC & BCLC-B & BCLC-B & BCLC- B & BCLC-C & BCLC-C \\
\hline Cause of death & $\mathrm{HCC}$ & $\begin{array}{l}\text { Hemorrhagic cerebrovascular } \\
\text { accident in the setting of COVID- } \\
\qquad 19 \text { infection }\end{array}$ & MI & Alive & Alive \\
\hline
\end{tabular}

Notes: *Age at diagnosis of advanced HCC, **lf cirrhosis present.

Abbreviations: TACE, transarterial chemoembolization; T, tremelimumab; D, durvalumab; PD, progressive disease; ICl, immune checkpoint inhibitor; CP, Child-Pugh; RFA, radiofrequency ablation; HBV, hepatitis $\mathrm{B}$ virus; $\mathrm{HCV}$, hepatitis $\mathrm{C}$ virus; SBRT, stereotactic body radiation therapy; TRCI05, (carutoximab) monoclonal antibody to endoglin (CDI05); BCLC, Barcelona Clinic Liver Cancer; HCC, hepatocellular carcinoma; MI, myocardial infarction.

to ICI, ${ }^{7}$ our data shows the existence of a subgroup within the responders that will have an overall survival much longer than described in the literature. Patient age, sex and duration of prior treatment with sorafenib were not associated with length of survival. Higher AFP level is generally considered to be a biomarker associated with a decreased overall survival in HCC; $;$, the AFP level in our patients did not show a correlation with survival. Our analyses showed that patients with a higher burden of disease did not necessarily die earlier, as may be expected. Based on a limited number of patients, we propose that a response to treatment is more likely to be associated with a longer survival compared to stable disease or progressive disease, although this did not reach statistical significance. There was an association between IrAEs-3/4 and a long-term overall survival; both patients who presented with IrAEs-3/4 had a long overall survival. This result is clearly hypothesis-generating and would need to be confirmed in an independent subsequent study before suggesting this association is truly meaningful. Interestingly, the appearance of IrAEs upon treatment with anti-PD-1 and anti-PD-L1 antibodies, ${ }^{10,11}$ such as durvalumab, has also correlated with improved outcomes such as longer OS, higher response rates and longer progression-free survival in various cancers, ${ }^{12,13}$ including non-small-cell 
lung cancer ${ }^{14-17}$ and melanoma. ${ }^{18}$ IrAEs are considered a potential marker for response to ICI, with the caveat that they present themselves upon treatment. Patients who respond to ICI may be more likely to have what is considered to be a responsive immune system and a higher incidence of autoimmunity when exposed to immunotherapy as a result of activated $\mathrm{T}$ cells targeting antigens present on both tumor and inflamed organ resulting in IrAEs as well as clinical response to treatment. ${ }^{19,20}$ However, the exact mechanism has not been described. Mixed results are reported in the literature on the association between antiCTLA4 antibodies such as tremelimumab, IrAEs and treatment efficacy, although there seems to be an overall association between IrAEs and an improved survival. ${ }^{21-24}$ The predictive value of IrAEs in patients treated with ICI continues to be studied.

\section{Conclusion}

The cases in our analysis represent extraordinary defiance of the usual predicted dismal course of advanced HCC. Our analysis further highlights the current need to identify markers for HCC patients that may derive benefit in overall survival with immunotherapy treatment.

\section{Ethics Statement}

The study was conducted according to the guidelines of the Declaration of Helsinki and approved by the Institutional Review Board of the National Cancer Institute (protocol 203 codes P12113 (13-c-0120) ref 325796 , date of approval 3/23/2013; P162680 (16c-0135) ref 204357115, date of approval 6/8/2016).

\section{Informed Consent Statement}

Informed consent was obtained from all subjects involved in the study.

\section{Author Contributions}

All authors made substantial contributions to conception and design, acquisition of data, or analysis and interpretation of data; took part in drafting the article or revising it critically for important intellectual content; agreed to submit to the current journal; gave final approval of the version to be published; and agree to be accountable for all aspects of the work.

\section{Funding}

This research was supported by the Intramural Research Program of the NIH, National Cancer Institute, Center for Cancer Research. The content of this publication does not necessarily reflect the views or policies of the Department of Health and Human Services, nor does mention of trade names, commercial products, or organizations imply endorsement by the US Government.

\section{Disclosure}

The authors declare no conflicts of interest.

\section{References}

1. Villanueva A, Longo DL. Hepatocellular carcinoma. $N$ Engl J Med. 2019;380:1450-1462. doi:10.1056/NEJMra1713263

2. Finn RS, Qin S, Ikeda M, et al. Atezolizumab plus bevacizumab in unresectable hepatocellular carcinoma. $N$ Engl $J$ Med. 2020;382:1894-1905. doi:10.1056/NEJMoa1915745

3. Yau T, Kang YK, Kim TY, et al. Efficacy and safety of nivolumab plus ipilimumab in patients with advanced hepatocellular carcinoma previously treated with sorafenib: the checkmate 040 randomized clinical trial. JAMA Oncol. 2020;6(11):e204564. doi:10.1001/ jamaoncol.2020.4564

4. Zhu AX, Finn RS, Edeline J, et al. Pembrolizumab in patients with advanced hepatocellular carcinoma previously treated with sorafenib (KEYNOTE-224): a non-randomised, open-label Phase 2 trial. Lancet Oncol. 2018;19:940-952. doi:10.1016/S1470-2045(18)30351-6

5. Duffy AG, Ulahannan SV, Makorova-Rusher O, et al. Tremelimumab in combination with ablation in patients with advanced hepatocellular carcinoma. $J$ Hepatol. 2017;66:545-551. doi:10.1016/j. jhep.2016.10.029

6. Lencioni R, Montal R, Torres F, et al. Objective response by mRECIST as a predictor and potential surrogate endpoint of overall survival in advanced HCC. J Hepatol. 2017;66:1166-1172. doi:10.1016/j.jhep.2017.01.012

7. El-Khoueiry AB, Sangro B, Yau T, et al. Nivolumab in patients with advanced hepatocellular carcinoma (CheckMate 040): an open-label, non-comparative, Phase 1/2 dose escalation and expansion trial. Lancet. 2017;389:2492-2502. doi:10.1016/S0140-6736(17)31046-2

8. Zhu AX, Kang YK, Yen CJ, et al. Ramucirumab after sorafenib in patients with advanced hepatocellular carcinoma and increased alpha-fetoprotein concentrations (REACH-2): a randomised, double-blind, placebo-controlled, Phase 3 trial. Lancet Oncol. 2019;20:282-296. doi:10.1016/S1470-2045(18)30937-9

9. Tangkijvanich P, Anukulkarnkusol N, Suwangool P, et al. Clinical characteristics and prognosis of hepatocellular carcinoma: analysis based on serum alpha-fetoprotein levels. J Clin Gastroenterol. 2000;31:302-308. doi:10.1097/00004836-200012000-00007

10. Kudo M, Finn RS, Qin S, et al. Lenvatinib versus sorafenib in firstline treatment of patients with unresectable hepatocellular carcinoma: a randomized phase 3 non-inferiority trial. Lancet. 2018;391 (10126):1163-1173. doi:10.1016/S0140-6736(18)30207-1

11. Maher VE, Fernandes LL, Weinstock C, et al. Analysis of the association between adverse events and outcome in patients receiving a programmed death protein 1 or programmed death ligand 1 antibody. $J$ Clin Oncol. 2019;37:2730-2737. doi:10.1200/ JCO. 19.00318

12. Rogado J, Sanchez-Torres JM, Romero-Laorden N, et al. Immunerelated adverse events predict the therapeutic efficacy of anti-PD-1 antibodies in cancer patients. Eur J Cancer. 2019;109:21-27. doi:10.1016/j.ejca.2018.10.014

13. Zhou X, Yao Z, Yang H, Liang N, Zhang X, Zhang F. Are immune-related adverse events associated with the efficacy of immune checkpoint inhibitors in patients with cancer? A systematic review and meta-analysis. BMC Med. 2020;18:87. doi:10.1186/ s12916-020-01549-2 
14. Baldini E, Lunghi A, Cortesi E, et al. Immune-related adverse events correlate with clinical outcomes in NSCLC patients treated with nivolumab: the Italian NSCLC expanded access program. Lung Cancer. 2020;140:59-64. doi:10.1016/j.lungcan.2019.12.014

15. Toi Y, Sugawara S, Kawashima Y, et al. Association of immune-related adverse events with clinical benefit in patients with advanced non-small-cell lung cancer treated with nivolumab. Oncologist. 2018;23:1358-1365. doi:10.1634/theoncologist.2017-0384

16. Grangeon M, Tomasini P, Chaleat S, et al. Association between immune-related adverse events and efficacy of immune checkpoint inhibitors in non-small-cell lung cancer. Clin Lung Cancer. 2019;20:201-207. doi:10.1016/j.cllc.2018.10.002

17. Sato K, Akamatsu H, Murakami E, et al. Correlation between immune-related adverse events and efficacy in non-small cell lung cancer treated with nivolumab. Lung Cancer. 2018;115:71-74. doi:10.1016/j.lungcan.2017.11.019

18. Okada N, Kawazoe H, Takechi K, et al. Association between immune-related adverse events and clinical efficacy in patients with melanoma treated with nivolumab: a multicenter retrospective study. Clin Ther. 2019;41:59-67. doi:10.1016/j.clinthera.2018.11.004

19. Das S, Johnson DB. Immune-related adverse events and anti-tumor efficacy of immune checkpoint inhibitors. $J$ Immunother Cancer. 2019;7:306. doi:10.1186/s40425-019-0805-8
20. Yoest JM. Clinical features, predictive correlates, and pathophysiology of immune-related adverse events in immune checkpoint inhibitor treatments in cancer: a short review. Immunotargets Ther. 2017;6:73-82. doi:10.2147/ITT.S126227

21. Passat T, Touchefeu Y, Gervois N, Jarry A, Bossard C, Bennouna J. [Physiopathological mechanisms of immune-related adverse events induced by anti-CTLA-4, anti-PD-1 and anti-PD-L1 antibodies in cancer treatment]. Bull Cancer. 2018;105:1033-1041. French. doi:10.1016/j.bulcan.2018.07.005

22. Downey SG, Klapper JA, Smith FO, et al. Prognostic factors related to clinical response in patients with metastatic melanoma treated by CTL-associated antigen-4 blockade. Clin Cancer Res. 2007;13:6681-6688. doi:10.1158/1078-0432.CCR-07-0187

23. Attia P, Phan GQ, Maker AV, et al. Autoimmunity correlates with tumor regression in patients with metastatic melanoma treated with anti-cytotoxic T-lymphocyte antigen-4. $J$ Clin Oncol. 2005;23:6043-6053. doi:10.1200/JCO.2005.06.205

24. Weber JS, O'Day S, Urba W, et al. Phase I/II study of ipilimumab for patients with metastatic melanoma. $J$ Clin Oncol. 2008:26:5950-5956. doi:10.1200/JCO.2008.16.1927
Journal of Hepatocellular Carcinoma

\section{Publish your work in this journal}

The Journal of Hepatocellular Carcinoma is an international, peerreviewed, open access journal that offers a platform for the dissemination and study of clinical, translational and basic research findings in this rapidly developing field. Development in areas including, but not limited to, epidemiology, vaccination, hepatitis therapy, pathology

\section{Dovepress}

and molecular tumor classification and prognostication are al considered for publication. The manuscript management system is completely online and includes a very quick and fair peer-review system, which is all easy to use. Visit http://www.dovepress.com/ testimonials.php to read real quotes from published authors. 